\title{
LOS FINES DE LA GEOGRAFÍA
}

\author{
Jorge Olcina Cantos \\ Carlos Javier Baños Castiñeira \\ Instituto Universitario de Geografía \\ Universidad de Alicante
}

\section{RESUMEN}

La aparición de la teoría de las revoluciones científicas de Thomas S. Kuhn supuso una intensa alteración para la didáctica de las ideas del pensamiento de las ciencias —entre ellas, la geografía-; desde entonces éste se presenta como una sucesión de paradigmas. El trabajo indaga sobre la bondad de la incorporación del sistema de paradigmas a la epistemología geográfica y presenta algunos ejemplos de desajuste del mismo. Se valora, por último, la necesidad de la geografía en el momento presente, el papel de las ideologías en el pensamiento geográfico, los fines actuales de la disciplina geográfica y su más que imposible fin.

Palabras clave: pensamiento geográfico, paradigmas, ideologías, fin de la geografía.

\begin{abstract}
The adaptation of Kuhn's scientific revolutions theory causes an intense alteration for the didactic manner of expound ideas of geographic thought; since then, these knowledge come out like a succession of paradigms. This thinking investigates on the goodness of adaptation of paradigms system to geographical knowledge and contributes some examples of up setting of this one. The paper, finally, values the necessity of geographical discipline at the present time, the role of ideologies in the geographic thought, the present aims of geography and the impossible end of this essential knowledge.

Key words: geographic thought, paradigms, ideologies, end of geography.

«La Geografía estudia la distribución del hombre en la superficie terrestre, explica la diversidad que se advierte en su distribución y en sus formas de vida, relacionándolas con otros diversos factores geográficos. Esto nos lleva a inquirir la acción recíproca que ejercen las influencias naturales y las fuerzas humanas»
\end{abstract}

Norbert Krebs. Geografía Humana, 1931. 
«El fin de la historia será un tiempo muy triste. La lucha por el reconocimiento, la voluntad de arriesgar la vida de uno por un fin puramente abstracto, la lucha ideológica mundial que pone de manifiesto bravura, coraje, imaginación e idealismo serán reemplazados por cálculos económicos, la eterna solución de problemas técnicos, las preocupaciones acerca del medio ambiente y la satisfacción de demandas refinadas de los consumidores... Puedo sentir en mí mismo y ver en otros que me rodean una profunda nostalgia por el tiempo en el cual existía la historia. Tal nostalgia de hecho continuará alimentando la competición y el conflicto incluso en el mundo post-histórico por algún tiempo... Quizás esta misma perspectiva de siglos de aburrimiento en el fin de la historia servirá para hacer que la historia comience una vez más».

Francis Fukuyama. El fin de la historia y el último hombre, 1991

\section{1. ¿Una geografía de paradigmas?}

La Geografía, junto a la Historia, es, tal vez, una de las pocas disciplinas científicas que constantemente se pregunta sobre su esencia y función y además estos interrogantes tienen, casi siempre, un fondo de desesperanza, de continua recriminación sobre su valor en el universo de las ciencias y su necesidad en cada momento histórico. El primer aspecto - la continua reflexión - ha resultado indispensable y positivo para su propio avance como modo de entender la realidad; el segundo, la constante recriminación sobre su función, ha empobrecido en no pocas ocasiones este debate.

Desde hace una década asistimos a un menor interés por el pensamiento geográfico; al menos eso traduce la lectura de la bibliografía geográfica internacional. Parece como si el desmembramiento de las ideas y corrientes de la izquierda científica — la que más ha animado la reflexión geográfica durante los últimos treinta años- en relación con la caída de los regímenes comunistas europeos, hubiera sumido la reflexión geográfica y, en general, el pensamiento occidental en una crisis de identidad.

Las bondades de la sociedad «post» occidental no contribuyen mucho a la práctica de la reflexión conceptual. No está de moda pensar. ¿Para qué pensar? En un mundo telemático que dispone de información al instante, no parece que resulte necesario pergeñar ideas, proponer reflexión. Nos hemos acostumbrado a obtener ideas de forma instantánea y, como mucho, a comentar, a opinar sobre ellas. Pero se nos ha olvidado - no lo creemos necesario- presentar ideas propias. Todo es instantáneo y perecedero; si surge una idea, es objeto inmediato de crítica y se agota al poco tiempo. El pensamiento, cierto es, es libre; pero de tan libre, ha tornado en «librepensamiento», nos hemos liberado de pensar. Se ha recuperado, en unamuniana frase, aquello de «que piensen ellos». La sociedad postmoderna es una sociedad de la INFORMACIÓN, pero no del PENSAMIENTO, no de la inquietud reflexiva. Hemos olvidado la máxima kantiana según la cual para avanzar como civilización debemos tener el valor de servirnos de nuestra propia razón. Y la civilización es, en esencia, el conjunto de modos de actuar y PENSAR comunes a un grupo social.

La Geografía no ha sido ajena a esta corriente «liberalizadora» del pensamiento. Salvo contadas excepciones, los trabajos publicados se vuelcan en el análisis y descripción de procesos territoriales. Al menos eso parece traducirse de la consulta de los títulos aparecidos en los últimos años. En el panorama internacional siguen resultando fundamentales los manuales de teoría de la geografía de Johnston (1994) o Claval (1995, 1999), que han encontrado eco de buena reflexión española en los trabajos de Ortega Valcárcel (2000), López Trigal y Benito del Pozo (1999), Nogue y Rufí (2001) o García Álvarez (2002). Asimismo, las revistas Progress in Human Geography (en su sección «Progress reports»), 
Herodote, Antipode o la española Documents d'Anàlisi Geografica dedican especial atención a las cuestiones de la epistemología geográfica, editando las novedades que se producen en el edificio del pensamiento geográfico. En el resto de revistas geográficas, nacionales e internacionales, las cuestiones relativas a la teoría de la geografía ocupan, en el mejor de los casos, un $10 \%$ del total de trabajos editados durante los últimos cinco años (vid. tabla 1).

Tabla 1

RELACIÓN DE ARTÍCULOS SOBRE TEORÍA DE LA GEOGRAFÍA PUBLICADOS EN DIFERENTES REVISTAS GEOGRÁFICAS (1998-2002)

\begin{tabular}{|c|c|c|}
\hline REVISTA & $\begin{array}{c}\text { TOTAL ARTÍCULOS } \\
\text { EDITADOS }\end{array}$ & $\begin{array}{c}\text { TRABAJOS SOBRE TEORÍA } \\
\text { DE LA GEOGRAFÍA }\end{array}$ \\
\hline Annales de Geographie & 162 & 6 \\
\hline $\begin{array}{c}\text { Annals of the Association } \\
\text { of American Geographers }\end{array}$ & 175 & 6 \\
\hline Estudios Geográficos & 118 & 8 \\
\hline Ería & 91 & 5 \\
\hline Boletín de la AGE* & 35 & 5 \\
\hline Investigaciones Geográficas & 100 & \\
\hline
\end{tabular}

* sólo se han revisado los trabajos en los 4 números misceláneos editados en el intervalo de análisis considerado. Debe recordarse, sin embargo, que el Boletín de la AGE ha editado un número monográfico sobre la «región» (n⿳⺈⿴囗十一 32) y otro sobre la «geografía cultural» ( $n^{\circ}$ 34) donde se contienen diversas aportaciones sobre teoría de la geografía.

Elaboración propia.

Ello no tiene porque significar nada negativo para los estudios geográficos. Antes al contrario asistimos a una prolífica generación de trabajos de auténtica geografía, esto es, de campo, de análisis y de síntesis sobre hechos geográficos concretos, sobre dinámicas territoriales a diversas escalas. En los últimos años ha habido más reflexión sobre el acto y menos sobre la potencia; es decir, se explican hechos y no tanto modos de interpretar esos hechos. Esto resulta muy evidente en la geografía española; menos en la francesa o en la anglosajona donde una serie de autores han mantenido la tradición del pensamiento geográfico durante los últimos años.

Una explicación posible de esta fase de atonía reflexiva puede estar en la propia manera que ha adoptado la geografía desde los años sesenta para el análisis de sus avances de pensamiento; esto es, la explicación de la epistemología geográfica a partir de la teoría de los paradigmas.

De esta manera ha terminado calando una división del pensamiento geográfico en dos grandes etapas: la pre-científica y la científica, y, en esta última, la organización en períodos que responden a una determinada apoyatura filosófica o, como denominó Kuhn, paradigmas. No hay manual de teoría de la geografía o historia del pensamiento geográfico que no incluya, desde los años sesenta, esta división en etapas y corrientes. Por doquier se acepta el brusco corte que considera un antes y un después de Humboldt y Ritter en el desarrollo científico de la geografía. 
De entrada, resulta poco apropiada esta división en dos grandes etapas: precientífica y científica; esta última inaugurada por Humboldt y Ritter con el avance del s. XIX. Es cierto que en la larga etapa anterior — ¿precientífica?-, no hay una sistematización precisa, no hay paradigmas, hay carencia de aparataje y de mediciones exactas, pero hay preocupación por entender el mundo conocido y desconocido, hay inquietud por calibrar sus dimensiones, por medir distancias, en definitiva, hay explicación de hechos geográficos. La evolución del pensamiento científico (geográfico, en nuestro caso) es una lucha por mejorar los conocimientos de épocas precedentes, es, en suma, un avance constante en la búsqueda de respuestas a las inquietudes del hombre. En las distintas épocas históricas el objetivo final ha sido idéntico: ensanchar el conocimiento humano del mundo habitado y habitable; lo que ha variado ha sido la posibilidad de disponer de medios técnicos cada vez más precisos. Y ello se ha acompañado de nuevas maneras de interpretar la realidad; de nuevas formas de pensar.

Este proceso, generalmente pausado y progresivo, se ha interpretado, sin embargo, a partir de los años sesenta, como una sucesión de rupturas, a partir de la incorporación de las ideas de Kuhn. Se habla de «revoluciones» que hacen tambalear el estado «normal» de la ciencia. Resulta así una exposición, sin duda, más atractiva de la evolución del pensamiento científico pero tal vez más alejada de la verdadera realidad del devenir de esa ciencia. Como en las divisiones de las grandes épocas históricas, el sistema de paradigmas permite animar el relato de la evolución epistemológica de las disciplinas científicas, particularmente de los últimos sesenta años.

Y éste es el gran mérito de las ideas de Kuhn; cuestión distinta es la valoración de la bondad de las etapas establecidas en el discurso de explicación de la evolución del pensamiento de una ciencia, —en nuestro caso, de la geografía-. Y ahí está la labor del geógrafo preocupado por la evolución epistemológica de su disciplina: valorar si la actual forma de explicar los avances epistemológicos de la geografía es adecuada. En otras palabras, si es apropiada la división en etapas de pensamiento que ofrece la actual teoría de la geografía; si realmente son tan «revolucionarias» las obras que marcan el tránsito de una etapa a otra. Y es aquí donde se pueden proponer visiones alternativas. Sea como fuere, el grado de cientifismo en geografía no debe establecerse en función de mejoras técnicas o la aparición de paradigmas, sino de la valoración de la calidad de los trabajos dedicados a explicar lo esencial: las relaciones entre el medio y el hombre, en cada época histórica.

El estudio y análisis de la evolución de la geografía como ciencia, entendida ésta como la sucesión de distintas escuelas de pensamiento relativamente hegemónicas, de sus bases epistemológicas y de la relación de éstas en los diferentes marcos generales del pensamiento científico e intelectual, se ha presentado, desde el alumbramiento de los presupuestos neopositivistas, como la configuración de una diversidad de corrientes geográficas, caracterizadas en gran medida por su estanqueidad, su definición por oposición a otras corrientes y su correlación íntima con otras disciplinas, afines en mayor o menor medida, por encima, incluso, de los lazos que les pudieran unir con la propia geografía.

En efecto, una de las primeras conclusiones que se extraen habitualmente del estudio de la evolución de la geografía es su constante explicación a partir de dicotomías y dualidades, que la han definido como ciencia. Así, el nacimiento de la geografía en Grecia ya conoce una de estas distinciones: Geografía matemática y astronómica frente a Corografía de tradición topográfica; Geografía General opuesta a Geografía Especial, o Universal y Particular, claramente explicitada por Varenio en el siglo XVII; la oposición entre Determinismo-Positivismo y Posibilismo, que marcará en buena parte el desarrollo de la geografía durante el siglo XX; la prolongación del debate entre determinismo y posibilismo desarrollado desde los años cincuenta del pasado siglo, planteado en clave de geografía 
sistemática y objetiva frente a una geografía social y subjetiva. Asimismo, durante la etapa fundacional decimonónica, la geografía posee importantes lazos que la ligan a las ciencias naturales, geología y biología; el proyecto cognoscitivo de la geografía durante el tránsito del siglo XIX al XX y primeras décadas de éste, encuentra en la historia buena parte de su bases teóricas y metodológicas; la renovación del positivismo acaecido tras la finalización de la Segunda Guerra Mundial, basará su discurso en los avances propiciados desde las matemáticas y la física; los presupuestos geográficos que, como rechazo a la visión analítica positivista, se refuerzan a partir del decenio de los años setenta del siglo XX, estarán íntimamente ligados a la psicología y la antropología, caso de las corrientes humanistas, o guiados desde una lectura político-económica del espacio y la sociedad, que tienen en la denominada geografía (o geografías) radical, su máximo exponente.

Este planteamiento descansa, como se ha señalado, en la utilización de la teoría epistemológica del paradigma como base de la explicación evolutiva de las ciencias. La asimilación del concepto de paradigma, acuñado por Thomas S. Kuhn, para la disciplina geográfica corresponde a la publicación en 1967 de la obra de Peter Haggett y Richard J. Chorley «Models in geography». Se trata, por tanto, de un modelo explicativo desarrollado en el seno de las corrientes analíticas del positivismo lógico, que encontrarán en los presupuestos y tesis de Kuhn la fórmula idónea para integrar a la geografía en el campo de las ciencias, objetivo perseguido con afán en la Nueva Geografía ${ }^{1}$.

En síntesis, los presupuestos básicos de los planteamientos de Thomas Kuhn, desarrollados en su conocida obra La estructura de las revoluciones científicas, publicada originalmente en 1962, parten de la necesidad de modificar la forma de entender la historia de la ciencia. Kuhn rechaza que la ciencia haya evolucionado como una acumulación de hechos, teorías y resultados, pues ello implicaría asumir que teorías e ideas falsas han tenido similar validez que aquéllas que resultaron acertadas. Niega, por tanto, el discurso de una ciencia que evoluciona mediante un proceso acumulativo de teorías, descubrimientos e inventos individuales. Frente a esa concepción «sumatoria» propone una comprensión de la historia de la ciencia descrita a partir de las nociones de ciencia normal y ciencia revolucionaria, explicadas ambas mediante el concepto clave de «paradigma». De esta forma, las ciencias evolucionarían en un ciclo ciencia normal-crisis-revolución-ciencia normal.

Los momentos de ciencia normal, los más frecuentes, se caracterizan por un reconocimiento general por parte del colectivo científico de cuáles son los problemas susceptibles de ser estudiados y un acuerdo universal sobre el método de trabajo. Esto es, un reconocimiento del «paradigma» científico imperante. Así, el paradigma se define por consenso entre la comunidad científica como la forma en que «debe hacerse ciencia», con un doble contenido: el acuerdo existente sobre las técnicas, los valores y las creencias compartidas por los miembros de esa comunidad científica, lo que Kuhn denomina «Matriz Disciplinar», que incluye las leyes, definiciones y modelos aceptados; y, en segundo lugar, los «paradigmas como ejemplares», es decir, la manera en la que se utilizan las teorías científicas, qué uso se les da, cómo se transmite ese conocimiento científico. Para Kuhn los paradigmas poseen varias funciones: 1) semántica, pues ofrecen un léxico o código de transmisión común, 2) de identificación de los problemas que

1 Así lo indican Hagget y Chorley: «En la actualidad, se distingue entre las humanidades, que tratan de lo que tienen un carácter único y no recurrente, y las ciencias que buscan el establecimiento de conclusiones generales para los acontecimientos y procesos repetitivos. La geografía contemporánea atraviesa por este abismo aparente que hay que salvar o, de lo contrario, se producirá la desmembración de la disciplina tal como existe hoy» (HAGGETT Y CHORLEY, 1971: 7). 
deben investigarse y 3) de evaluación de esa investigación, esto es, de valoración de cuál es el nivel de validez de la misma.

Han sido múltiples las críticas planteadas a las tesis de Kuhn, así como las señaladas para la adaptación concreta de éstas a la ciencia geográfica. Entre las primeras autores como Margaret Masterman, Imre Lakatos o el propio Karl Popper, plantean diversas objeciones a la teoría de Kuhn. Así, Masterman considera la definición del término «paradigma» notablemente confusa, pues llega a reconocer hasta veintiuna acepciones diferentes del término «paradigma» en la primera formulación de las tesis de $\mathrm{Kuhn}^{2}$, lo que incluso obligó a éste a reformular en años siguientes sus teorías. Entre las críticas que niegan el carácter «revolucionario» e instantáneo en la evolución de las ciencias, Lakatos ha señalado que es habitual que durante tiempo prolongado distintas concepciones, proyectos o, en definitiva, paradigmas, compartan —compitiendo - un mismo periodo cronológico, hasta que uno de ellos, transcurrido un largo proceso, se imponga a los demás. Popper, por su parte, critica tanto los planteamientos de Kuhn como los de Lakatos al sostener que la ciencia avanza desde la fase de la experimentación, nunca mediante la sustitución de ideas y que debería tener un carácter crítico, dirigiendo los experimentos hacia la refutación y no hacia la verificación de las teorías imperantes (UNWIN, 1995: 51).

En el estricto campo de la geografía David R. Stoddart considera que la difusión del vocabulario y la teoría de Kuhn, iniciada por Haggett y Chorley en 1967 (UNWIN, 1995: 50) y su aceptación, se realizó sin que se produjese examen crítico alguno de sus contenidos teóricos. El propio Stoddart señala que la mayor comprensión de la evolución de la geografía en los últimos cien años y de las relaciones establecidas entre los diferentes geógrafos hace menos útil y apropiado el uso del concepto paradigma (CAPEL, 1981: 257). En realidad, cuanto más se profundiza en la historia de la geografía, menos válido parece resultar la aplicación de las teorías de Kuhn en geografía, o al menos la aplicación que se le ha dado hasta el momento. En primer lugar, debido a la profusión de paradigmas geográficos surgidos en el último medio siglo. Kuhn limita el establecimiento de «teorías paradigmáticas» a logros de carácter universal (Teoría de la gravitación universal, Teoría de la relatividad), sin embargo en geografía se ha utilizado el término tanto para identificar a las grandes corrientes de pensamiento geográfico (determinismo, paradigma regional, los paradigmas basados en modelos propios del positivismo lógico, geografías radicales, geografías humanísticas) como para, prácticamente, cada ámbito de estudio e investigación de la disciplina (paradigmas locacionales, para el estudio de los transportes, de las industrias). Se da, por tanto, un reduccionismo en la conceptualización del paradigma en geografía, identificándolo en ocasiones con los momentos de ciencia normal y en otras exclusivamente con métodos y teorías de trabajo e investigación.

Otra de las dificultades en la adaptación de la concepción revolucionaría de la ciencia a la geografía se refiere a la convivencia de distintos «paradigmas» o formas de hacer geografía en el tiempo. En efecto, Kuhn sugiere que el encumbramiento de un paradigma, que dará paso a un periodo de ciencia normal, supone, paralelamente, la desaparición de los supuestos planteados por el paradigma anterior, la modificación de la forma en que se resolvían los problemas e incluso de la percepción de cuáles son los problemas que deberían ser resueltos. Sin embargo, la historia de la geografía no se compadece con ello. Distintas formas de hacer geografía han convivido, y conviven, durante periodos de tiempo superiores incluso a los cincuenta años. Bien es cierto que durante determinados periodos,

2 Si bien, Masterman no considera que todas sean excluyentes entre sí. Vid. MASTERMAN, M. (1970): «The nature of a paradigm», en Lakatos, I., y Musgrove, A. (eds.), Criticism and the growth of knowledge, Londres, Cambridge University Press, pp. 59-90. Citado en UNWIN, T. (1992): El lugar de la geografía, p. 50. 
alguna de esas formas hacer geografía ha mantenido un cierto status hegemónico (Geografía Regional en los primeros decenios del siglo veinte, la denominada Nueva Geografía tras la Segunda Guerra Mundial hasta el decenio de los años setenta del pasado siglo), de manera que se convertía en la corriente con mayor predicamento. Sin embargo, la preeminencia de alguna de estas corrientes no supuso la desaparición de las anteriores, bien por mantener herencias de corrientes pasadas o resultar de la evolución de éstas, caso de la Geografía Regional posibilista respecto al Determinismo ambiental de los últimos años del siglo XIX, bien por la persistencia de corrientes en una fase de relativa hegemonía de otra.

¿A qué se debe, por tanto, el éxito y la difusión de las teorías de Kuhn en la disciplina geográfica? La introducción de éstas coincide precisamente con el auge de la corriente de pensamiento geográfico que más y mejor puede identificarse con la idea de paradigma: la geografía cuantitativa de corte neopositivista surgida tras la Segunda Guerra Mundial. En efecto, el recurso al lenguaje matemático como léxico universal, la orientación «pragmática» en la selección de los problemas a los que dar respuesta, la enunciación de leyes y teorías como objetivo último planteado y la construcción modelos que pretendían ser generales parecen marcar un profundo cambio en la disciplina e introducirla directamente en el marco de las ciencias ${ }^{3}$, objetivo ampliamente perseguido por la geografía positivista, tanto del siglo XIX como del XX.

Sin embargo, a pesar de las notables transformaciones que sufrió la geografía con la aplicación de las teorías de la Escuela de Berlín y el Círculo de Viena, existen, incluso, argumentos que impiden sostener la idea del cambio paradigmático:

a) el objeto del estudio de la geografía continuó siendo el mismo, las relaciones entre las sociedades y el medio geográfico y su reparto sobre las distintas áreas de la superficie de la tierra. Permaneció como una disciplina integradora y sintetizadora de los problemas espaciales, que pretende ofrecer soluciones que la sociedad reclama para esas cuestiones.

b) si bien se produjeron grandes avances en cuanto a los métodos de trabajo con la matematización de la disciplina, el desarrollo de los modelos y la aplicación de la informática, especialmente exitosa en el caso de los Sistemas de Información Geográfica, el método básico de trabajo de la geografía continuó inalterable, pues el mapa, la escala, el trabajo de campo, el análisis y la síntesis permanecieron como la forma esencial de trabajar de los geógrafos.

c) la continuidad de otras corrientes geográficas, como la propia geografía regional, así como la aparición de otras nuevas (radicales, humanísticas) niegan a su vez el carácter revolucionario, según la conceptuación de Kuhn, de los presupuestos neopositivistas en geografía.

Parece, por tanto, poco adecuado el intento de explicación de la historia de la geografía y su pensamiento mediante la utilización de las teorías y conceptos desarrollados por Thomas S. Kuhn en su obra La estructura de las revoluciones científicas. Es innegable, sin embargo, que aquéllas han calado hondamente en nuestra ciencia. Quizá la explicación del porqué de ese éxito la diera ya Sttodart «Sugiero que una importante razón reside en la forma con que el concepto de revolución magnifica la propia imagen heroica de quienes se ven a sí mismos como innovadores y utilizan el término de paradigma en un sentido polémico, junto con el hecho de que la terminología de Kuhn suministra una justificación

3 Si se entiende la ciencia bajo una concepción exclusivamente racionalista y lógica. 


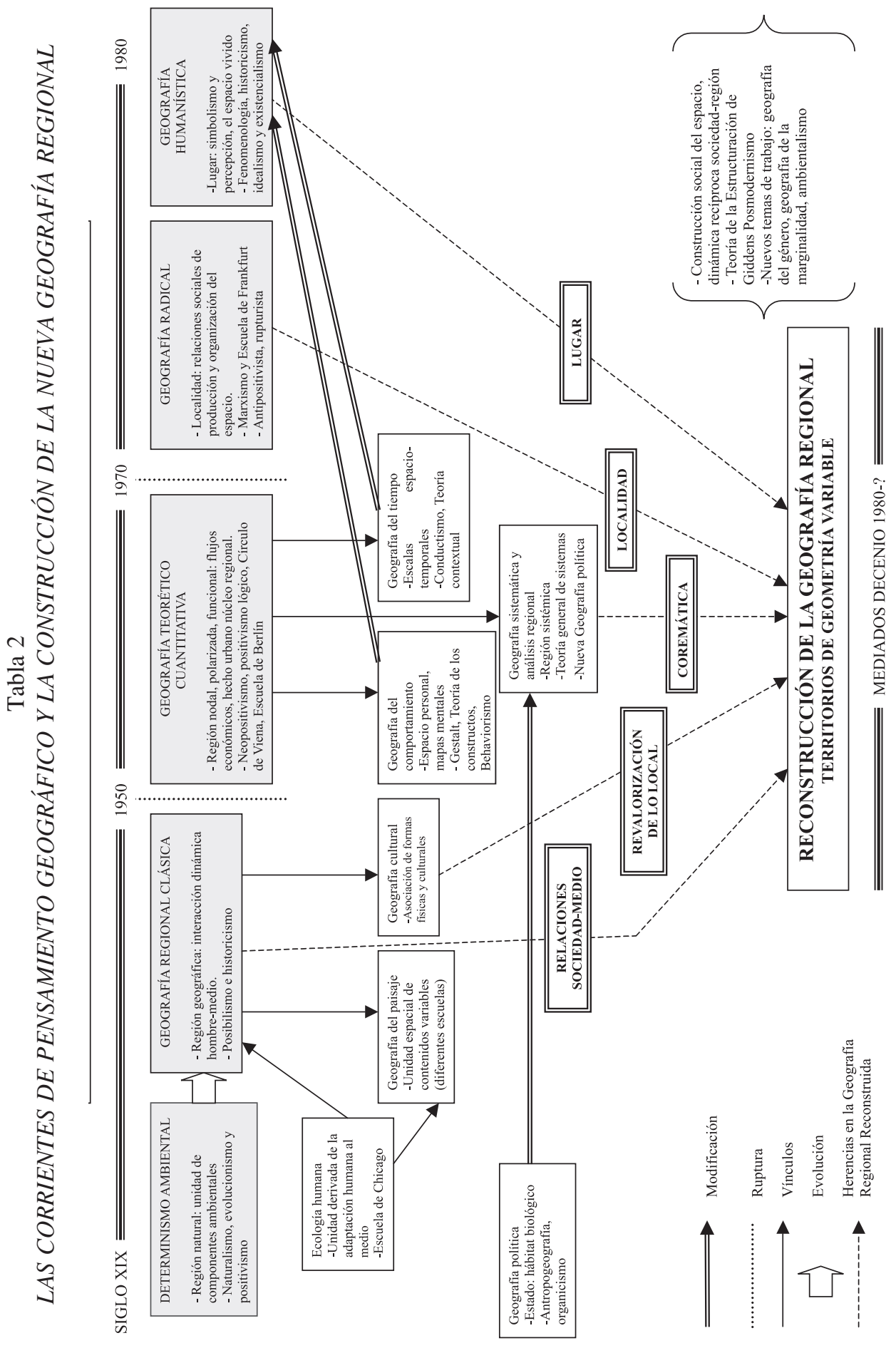


aparentemente científica para la innovación de cambios, más en el campo social que en el estrictamente científico ${ }^{4}$. Otra clave de este éxito está, sin duda, en las posibilidades de presentación didáctica del sistema de paradigmas.

No hay en geografía «revoluciones» que pongan en peligro el cimiento básico de la disciplina; hay adaptación a la realidad en cada momento y ello si implica cambios de enfoque en la manera de analizar las cuestiones geográficas...pero no cambios de base. Hay pues, incorporaciones de nuevas apoyaturas filosóficas para el estudio de los mismos fines. Y este es el gran mérito de la disciplina, lo que le otorga categoría de rama esencial del conocimiento humano.

\section{Falsos mitos en la evolución del pensamiento geográfico}

Se ha señalado que la manera — didáctica — de presentar la evolución del pensamiento geográfico puede no haber sido la más indicada para analizar el verdadero devenir de la reflexión llevada a cabo en esta disciplina científica. Y ello porque, al margen de resultar formalmente atractiva, ha dado una imagen excesivamente rupturista y esquemática de dicha evolución, ocultando avances o ignorando tradiciones arraigadas en la propia historia de la ciencia geográfica. Tres son las consecuencias fundamentales de este modo de hacer: a) se destacan los aspectos de enfrentamiento entre corrientes; b) se silencian avances de una corriente geográfica porque tienen lugar en la etapa de difusión de un nuevo paradigma; y c) se presentan nuevas lecturas de la tradición de pensamiento geográfico, como si estuvieran huérfanas de antecedentes. Hay algunos ejemplos en la evolución del pensamiento geográfico que pueden adornar esta afirmación.

Es el caso de la pretendida oposición entre las dos corrientes clásicas de la geografía, la naturalista, especialmente sustentada por los supuestos deterministas ambientales, inaugurada por Ratzel, y la perspectiva regional o corológica de corte posibilista. Es innegable que la transición entre los siglos XIX y XX supone una notable transformación de las bases cognoscitivas de la geografía. La crisis del pensamiento positivista decimonónico influyó, lógicamente, en el armazón teórico de la joven disciplina, de manera especial sobre la voluntad universalista de las construcciones geográficas, cuyo efecto será, en palabras de Carl Ortwin Sauer, «el proceso de repliegue dentro de un dominio reconocible», fenómeno, por tanto, de introducción de la geografía dentro de horizontes de pensamiento más limitados, del cual no duda Sauer en hacer a Alfred Hettner su máximo responsable epistemológico ${ }^{5}$. Por otra parte, las dudas sobre la validez de los presupuestos universalistas del positivismo tuvieron una segunda consecuencia para la geografía: la disgregación, diversificación y especialización en distintos campos del cuerpo del conocimiento geográfico, proceso que afecta tanto a la Geografía Física como a la Humana.

Sin embargo, admitiendo tales evidencias, no es menos cierto que la historia del pensamiento geográfico ha prestado más atención a los argumentos de ruptura y distanciamiento, en buena parte debido, como se ha señalado, a la propagación de las teorías de Kuhn, que a aquellos que demuestran la existencia de un proceso de continuidad y evolución. En este sentido cabe destacar, al respecto de la pervivencia de fundamentos de la geografía decimonónica en la disciplina durante las siguientes décadas, la concepción de la

4 STODDART, D.R. (1982): «El concepto de paradigma y la historia de la geografía» en Geocrítica, nº 40. Universidad de Barcelona.

5 SAUER, C. O. (1931): «Cultural Geography» en Encyclopaedia of the Social Sciences, Nueva York. Publicado en castellano «La Geografía Cultural» en GÓMEZ MENDOZA, J., MUÑOZ JIMÉNEZ, J., ORTEGA CANTERO, N. (1987): El pensamiento geográfico. (2ª ed.) Alianza, Madrid. Pp. 349-354. 
geografía como una ciencia integradora de los fenómenos físicos y humanos. Las diferencias en los proyectos cognoscitivos de las dos corrientes principales geográficas no deben ocultar que la base de los mismos se identifica claramente con ese objeto fundamental de trabajo. Uno de los nexos de unión entre ambos planteamientos puede hallarse en la perspectiva ecológica en geografía, desde una óptica ambientalista en el caso de las ideas propugnadas por la Escuela de Chicago, y desde una visión que prima lo social en el caso la geografía clásica francesa.

Asimismo, en ocasiones se ha interpretado de manera extrema el pensamiento y la obra de autores de ambas corrientes geográficas, de manera que permitiera un mejor encasillamiento de los mismos, facilitando el establecimiento de claras rupturas entre los diferentes periodos evolutivos de la geografía. Es el caso del padre del determinismo ambiental, Friedrich Ratzel. En él, la visión determinista aparece, a pesar de todo, ampliamente matizada por la importancia otorgada al nivel de desarrollo humano. Su concepción de la «influencia» que el medio ejerce sobre el hombre se aproxima notablemente al de las «relaciones» propuestas por los geógrafos regionales, sin duda más que al exacerbado determinismo defendido por algunos de sus seguidores: «Pero antes de dedicar un minuto más al examen de estos diversos tipos de influencia debemos hacernos una clara idea del hecho de que un pueblo no está expuesto a la influencia del clima de igual manera en todos los grados de su desarrollo. Sucede en un pueblo lo mismo que ocurre en un hombre individual, en el cual la fuerza de resistencia aumenta con su desarrollo y disminuye nuevamente con la edad». De la misma manera, no duda en erigir al hombre como el principal agente transformador de la naturaleza: «las plantas han influido sobre las plantas, los animales sobre los animales, y ambos entre sí recíprocamente, pero ningún otro ser ha actuado en tal medida y tan constantemente y sobre tantos otros seres como el hombre, el cual por ello ha transformado profundamente la faz viviente de la Tierra $»^{6}$.

Similar ha sido el tratamiento realizado a la obra del maestro de geógrafos franceses Paul Vidal de la Blache, en gran parte debido a Lucien Febvre, que presentó su pensamiento, como manera de ver la realidad de forma totalmente diferente, opuesta, a la de Ratzel; contribuyendo así a ensalzar a Vidal y «enterrando» al geógrafo alemán. Vidal libera al hombre de las cadenas deterministas que, según Ratzel, le ligaban a la naturaleza, introduce la contingencia como factor clave en la vida y la libertad humana. Sin embargo, no niega por completo los preceptos ambientalistas, pues sigue a Ratzel al considerar que el estudio de los pueblos primitivos permite un mejor conocimiento de las relaciones hombremedio, relaciones que serán de estrecha dependencia cuanto más primarias sean estas sociedades. Esta idea fue claramente expuesta años después por el profesor Terán «el posibilismo no significa la radical y sistemática negación de la influencia que los factores físicos pueden ejercer sobre la vida humana, sino la indagación, en cada caso, de su posible existencia, y de precisar el contorno y los límites de su actuación ${ }^{7} »$.

Son, por tanto, numerosos los ejemplos de esta lectura excesivamente «frentista» hecha de la evolución del pensamiento en geografía y ello a pesar de que la lectura más sosegada y reflexiva de los textos geográficos originales revela, como se ha indicado, que la tan pretendida oposición entre positivismo y posibilismo, entre la geografía sistemática y la geografía regional, de las concepciones nomotéticas e idiográficas, no resulta tan evidente

6 RATZEL, F. (1901): La tierra y la vida. Geografía comparada. Cit. en CAPEL, H. (1982). P. 285.

7 TERÁN, M. de (1957): «La causalidad en la Geografía Humana». Estudios Geográficos, 67-68, pp. 273308. Pp. 285. 
como dejan traducir las obras de la epistemología geográfica. Incluso aquellos autores considerados como los verdaderos inauguradores de las diversas corrientes no rechazan la necesidad de otras perspectivas en geografía. Así, Hettner reconoce la importancia de la geografía general como condición necesaria para abordar trabajos de geografía regional. El propio Fred K. Schaefer, iniciador de la denominada «Nueva Geografía» al trasvasar a la disciplina los supuestos filosóficos del Círculo de Viena, reconoce la necesidad de la región como laboratorio geográfico y no antepone la geografía sistemática a la regional: «porque, insistimos, la geografía regional es como el laboratorio en el que las generalizaciones del físico teórico deben soportar la prueba de la experimentación y la verdad. Parece que puede decirse, pues, como conclusión que la geografía regional y sistemática son aspectos inseparables e igualmente indispensables de nuestra disciplina» (SCHAEFER, 1974: 41). Asimismo, Hartshorne, con quien Schaefer se involucró en una agria polémica científica, pensaba, siguiendo a Hettner, que el análisis sistemático era indispensable para la síntesis regional.

La exposición «paradigmática» de la evolución del pensamiento geográfico ha tendido, asimismo, a silenciar aportaciones interesantes hechas durante una etapa de difusión de un paradigma, pero bajo los principios de otro anterior. Así, por ejemplo, en medio de la etapa de neopositivismo, de pasión por el número y la ley matemática, pocas veces se destaca que un buen número de geógrafos, la gran mayoría de los profesores de geografía de las universidades occidentales, seguían trabajando, a menudo ajenos a los nuevos vientos que llegaban allende el Atlántico. Se trabaja, así, dentro de los principios de la geografía regional, si bien, incorporando nuevas aproximaciones que enriquecen el modo de hacer de la región «clásica».

Es el caso del geógrafo inglés Roger Minshull, quien, en 1967, publica un manual de «Geografía Regional», de enorme interés por las ideas de renovación que aporta para la práctica regional ${ }^{8}$. En efecto, Minshull, siguiendo las ideas del geógrafo Whittlesey, propondrá una nueva unidad de análisis regional, el «compage». Se trata de un término de traducción difícil (área compacta), con el que se designa una extensión espacial que incluye todos los rasgos de los medios físicos, bióticos y sociales que están funcionalmente relacionados por la acción del hombre sobre la superficie terrestre. Minshull señala que la diferencia entre la región y el «compage» es la diferencia entre la teoría y la práctica, puesto que según este autor hasta ese momento el término región se ha empleado, según él, para denominar indistintamente a la totalidad de fenómenos que se dan en un área dada, mientras que la práctica demuestra que el análisis de la superficie terrestre cuando se analizan espacios geográficos concretos no requiere de esquemas fijos, sino que deben ir adaptándose en su estudio aquellos aspectos, en su orden correspondiente, que realmente resultan significativos en cada unidad de análisis. La expresión «compage», señala Minshull, se propone para referirse a un aspecto particular de la geografía regional, a un tipo particular de región que es bastante más familiar y, por encima de todo, para hacer mención a un método particular de trabajo. La tabla adjunta resume las ideas de Minshull sobre la región «tradicional» y su nueva propuesta de análisis regional (vid. tabla 3).

Es, en el fondo, una crítica al esquema regional clásico, cuya reiterada aplicación en investigaciones y manuales había derivado en una reiteración mecanicista. Concluye Minshull que la aproximación mediante «compages» permite otorgar mayor atención a tres

8 Vid. MINSHULL, R. (1967): Regional Geography. Theory and practice, Hutchinson University Library, London, $168 \mathrm{pp}$. 
Tabla 3

RENOVACIÓN DE LA GEOGRAFÍA REGIONAL EN LOS AÑOS SESENTA: EL «COMPAGE»DE MINSHULL

\begin{tabular}{|c|c|}
\hline REGIÓN TRADICIONAL & «COMPAGE» \\
\hline $\begin{array}{l}\text { - Importancia de la estructura del relieve } \\
\text { Énfasis en el área, forma, tamaño y posi- } \\
\text { ción } \\
\text { - Los límites de todas las cuestiones de aná- } \\
\text { lisis coinciden } \\
\text { - Relación rígida de elementos de análisis, } \\
\text { en número y orden } \\
\text { - Carácter enciclopédico y, por tanto, no } \\
\text { siempre inspirado } \\
\text { - Preocupación por el marco físico }\end{array}$ & $\begin{array}{l}\text { - Importancia de las cuestiones principales } \\
\text { como aspecto central de los análisis } \\
\text { - Énfasis en el área central y su carácter } \\
\text { - Definición a partir del límite de un aspec- } \\
\text { to de análisis } \\
\text { - Variación del número, del orden y del } \\
\text { énfasis de los elementos de análisis } \\
\text { - Presentación selectiva de aspectos de in- } \\
\text { terés genuinos } \\
\text { - Énfasis en la posición central que ocupa } \\
\text { el hombre en el espacio regional }\end{array}$ \\
\hline
\end{tabular}

Fuente: Minshull, 1967.

aspectos básicos del análisis regional (la mayor atención que debe prestarse a algunos aspectos de los espacios regionales, la ordenación de estos contenidos y el diferente énfasis en la presentación final) en contraste con el esquema regional clásico.

Otra propuesta de mayor repercusión que aparece en plena etapa neopositivista es la geografía zonal, surgida en Francia en la década de los sesenta, como intento muy digno por recuperar la «zona» como unidad de análisis geográfico. En Francia, país donde alcanzó mayor difusión, esta corriente de análisis geográfico era heredera de la llamada «geografía tropical», surgida aquí en la inmediata posguerra9 y que tuvo en la obra de P. Gourou su expresión temprana más destacada ${ }^{10}$. Los programas oficiales emanados de la reforma de la enseñanza superior puesta en marcha en Francia en 1966 sitúan en lugar de privilegio los enfoques geográficos zonales. En este contexto las editoriales Nathan y Armand Collin lanzan colecciones de manuales con dicha temática, entre los que descollan los trabajos de Viers (1969) y de Benchetrit, Cabot y Durand-Dastès (1970).

La Geografía zonal (del griego $\zeta \omega v \eta$, «ceñidor o cinturón») se presenta como el nexo de unión entre la Geografía general, que estudia los fenómenos en sus mecanismos de conjunto y la Geografía regional, que estudia la combinación de los diferentes fenómenos en espacios de orden inferior. La Geografía zonal propone despejar las características comunes que presentan ciertas porciones del globo delimitadas por líneas paralelas al ecuador. En estos trabajos, la zona se contempla como el espacio definido esencialmente a partir de ciertas características del clima (radiación, insolación y temperaturas). Asistimos, pues, a una revalorización de la división clásica griega del mundo en 3 zonas (zona tórrida, zona templada y zona fría) separadas entre sí por las líneas cartográficas maestras, es decir, ecuador, trópicos y círculos polares. Aunque la estructura de los trabajos no termina por

9 Recordemos que en la reunión de Washington (1952) la Unión Geográfica Internacional había creado una comisión dedicada al estudio del África Tropical y en la reunión de Río de Janeiro (1956) se creaba la comisión de «Regiones tropicales húmedas».

10 Vid. Gourou, P. (1947): Les pays tropicaux, P.U.F., París, 197 p. 
encontrar un esquema universal de análisis ${ }^{11}$, se pueden señalar algunos puntos comunes en su composición: a) incluyen un primer apartado en el que se ofrece un enfoque "general» donde se analizan, en primer lugar, los aspectos de la dinámica atmosférica que caracterizan cada una de las zonas, se explica cómo éstos inciden en la formación de los distintos tipos climáticos y, con ellos, de paisajes (físicos) contrastados; estos últimos definidos, básicamente, por características de suelo y vegetación; b) se analizan, a continuación, los «tipos de medios», donde se incluye un estudio detallado de los tipos de paisajes que se encuentran en una zona en relación con los rasgos climáticos, relieves, cursos fluviales, suelos y vegetación. Así, en el análisis de las zonas templadas y frías se incluyen, entre otros, los inlandsis, las tundras y bosques forestales, las regiones de clima mediterráneo, las praderas y las estepas templadas. Por su parte, en la zona cálida se estudian los medios hiper-húmedos, las plataformas tropicales, las regiones áridas cálidas y los medios cálidos modificados por la altitud.

La obra de Benchetrit, Cabot y Durand-Dastès (1970) sobre las regiones cálidas introdujo una novedad respecto al trabajo de Viers publicado una año antes, al incluir un tercer apartado en el que se estudian los problemas de desarrollo socio-económico propios de dicha zona. Así, con un sentido «generalista» se estudian la demografía, el legado histórico, agricultura, industria, poblamiento (urbanización) y desarrollo regional. De este modo, los trabajos zonales se basan en la descripción de un medio físico (el existente en el marco de la zona climática), analizando las formas de adaptación del hombre y de las sociedades a dicho medio.

Del conjunto de obras publicadas con este enfoque, P. Claval (1987) destaca la aportación de O. Ribeiro y S. Daveau sobre la zona intertropical húmeda, al ser la única que integró sin dificultad los objetivos de un enfoque zonal; es decir, se presentan con imparcialidad las diferentes partes del área interesada, tratando con idéntica acuidad las similitudes como las diferencias del sector de estudio y se apuesta por una aproximación específicamente cultural.

A pesar del interés didáctico que presentaba la Geografía zonal, hay que señalar el escaso eco que tuvo en la docencia universitaria de otros países occidentales, entre ellos España, y la nula proliferación de publicaciones con enfoque zonal aparecidas desde entonces en la bibliografía geográfica. Hay que mencionar, sin embargo, los intentos actuales de revisión de la Geografía zonal llevados a cabo en alguna obra de edición reciente, que, aunque con esquema renovado (sistémico), mantiene dicho enfoque como base para la explicación de territorios de la superficie terrestre afectados por un mismo fenómeno de origen natural. Es el caso del trabajo de Monique Mainguet (1995), en el que bajo el título El hombre y la sequía, se estudian los aspectos físicos y humanos de aquellos territorios planetarios tributarios de la aridez asociada a la presencia del cinturón de células de alta presión subtropical (ámbito intertropical) o a la aparición de fenómenos de abrigo circulatorio frente a las corrientes perturbadas del oeste (latitudes medias). En este caso, la zona objeto de estudio se extiende entre $20^{\circ}$ y $50^{\circ}$ de latitud norte y sur.

Por último, la exposición del pensamiento geográfico como sucesión de paradigmas tiende a ofrecer una idea de renovación constante de la disciplina a modo de sucesión de novísimas interpretaciones de las cuestiones geográficas que no tienen en cuenta la tradi-

11 Viers (1969) realiza únicamente un estudio de los rasgos del medio físico incluidos en una zona. Villacres Moscoso (1968) propone el siguiente esquema para el estudio de las zonas del mundo (clima, fitogeografía, zoogeografía, geografía humana y paisaje). Benchetrit et alt. (1970) señalan la necesidad de incluir el análisis de los aspectos humanos que se desarrollan en las regiones que integran una zona. 
ción epistemológica. Todo resulta excesivamente nuevo, huérfano de antecedentes. Y ello es una visión errónea de la evolución de las ideas practicadas en geografía.

Un ejemplo de esto es la presentación de los rasgos que caracterizan la denominada «nueva geografía cultural». Los últimos lustros del siglo XX y los primeros años del XXI son testigos de una proliferación de trabajos geográficos que se relacionan con una de las ramas clásicas de la disciplina, la Geografía Cultural. En efecto, tras haber constituido una de las líneas de trabajo más prolíficas y de gran brillantez del quehacer geográfico durante el primer tercio del pasado XX, la Geografía Cultural entró en crisis con el auge del positivismo lógico, que minimizó el estudio de las relaciones hombre-medio de la geografía y del componente histórico que las caracteriza, así como los enfoques subjetivos de la realidad. Sin embargo, a comienzos de los años setenta del pasado siglo, con el auge de las geografías humanistas, la Geografía Cultural conoce una revitalización que cristaliza a finales del siglo en lo que se ha dado en denominar «Nueva Geografía Cultural» o, en puridad, nuevas geografía culturales, derivadas del proceso de renovación de la geografía cultural.

Esta «nueva forma» de hacer geografía cultural mantiene, en buena medida, la herencia de los trabajos de principios del siglo XX, fundamentalmente por lo que se refiere a ciertos contenidos como la relación entre el medio y los seres humanos, la defensa de formas de producción tradicionales o los propios modelos de difusión cultural. Sin embargo, se añaden ahora enfoques nuevos que imprimen diferencias con la geografía cultural clásica. Los cambios sociales y económicos producidos en los últimos decenios (globalización, internacionalización empresarial, homogeneización cultural) han obligado a los geógrafos culturalistas a abandonar parte de su legado introduciendo nuevos temas de trabajo y metodologías distintas de las que aplicaran Ratzel, Sauer o Vidal de la Blache.

Esta renovación de los enfoques y contenidos de la Geografía Cultural tiene lugar, fundamentalmente, en el mundo anglosajón y en Francia. La denominada New Cultural Geography anglosajona, desarrollada a partir de mediados de los años ochenta del siglo $\mathrm{XX}$, cristaliza en el contexto de una agria polémica entre geógrafos de ambos lados del Atlántico. En efecto, esta nueva geografía cultural es fruto de los debates planteados entre geógrafos estadounidenses, preservadores de la herencia «saueriana» y británicos, donde la obra de Sauer apenas había tenido repercusión. En ambos casos se plantea, cada uno desde su postura, la necesaria renovación de los enfoques y los contenidos de la Geografía Cultural.

Para los «nuevos» geógrafos culturalistas, el centro de atención ya no serán las técnicas de producción o las instituciones sociales propias de un grupo. El interés se traslada hacia la comprensión de «la interpretación simbólica que los grupos o clases sociales dan del entorno, las justificaciones estéticas o ideológicas que proponen y el impacto de las representaciones en la vida colectiva» (CLAVAL, 1999: 53). Es en este contexto donde se sitúan los trabajos iniciales de Denis Cosgrove sobre la concepción, modelación y percepción del paisaje por parte de ingleses y venecianos durante el siglo XVII ${ }^{12}$ o los de James Duncan sobre la civilización cingalesa ${ }^{13}$. Por tanto, el énfasis se traslada desde los aspectos relativos a la cultura material hacia las interpretaciones de la cultura como ideología.

12 COSGROVE, D. (1984): Social Formation and Symbolic Landscape, Londres, Croom Helm.

13 DUNCAN, J. (1990): The City as Text: the Politics of Landscapes Interpretation in the Kandyan Kingdom, Cambridge, Cambridge University Press.

- (1992): «Re-presenting the Landscape: problems of reading the intertextual» en MONDADA, L.; PANESE, F. y SÖDERSTRÖM, O. (Dirs.) Paysage et crise de la lisibilité, Lausanne, Université de Lausanne, Institut de Géographie, pp. 81-93. 
La Geografía Cultural francesa, por su parte, es menos rupturista con el pasado. Se abandona, por amplio e impreciso, el concepto de género de vida, para pasar a interpretar las nuevas sociedades industriales y urbanizadas mediante el análisis de roles y las formas de administrar el tiempo. La vida de los individuos se muestra como la suma de diferentes particiones espacio-temporales, susceptibles de ser estudiadas individualmente. Ésa es, a grandes rasgos, la línea de trabajo que ha desarrollado Claval.

No obstante, el carácter más continuista — menos rupturista - de la nueva geografía cultural francesa respecto a la geografía cultural clásica no ha estado ajeno a tensiones. En un reciente artículo, Beatrice Collignon (COLLIGNON; 1999) recoge las distintas líneas de trabajo que se aprecian, en la actualidad, en la Geografía Cultural francesa: a) los análisis clásicos regionales en los que la cultura es el hecho esencial; b) la utilización de métodos cuantitativos de representación, que integran los fenómenos culturales en los análisis espaciales, próximos a los planteamientos coremáticos; c) la importancia de la percepción sensorial en la construcción de las relaciones con el territorio, lo que incluye los gustos y las prácticas alimentarias, y a la que en los últimos tiempos se añaden estudios sobre el olor; d) se mantiene la línea de trabajos iniciados en los años setenta del siglo XX sobre las representaciones, la plasmación de las realidades sociales sobre el paisaje, así como las relaciones entre representación, identidad y territorio; e) los análisis sobre el discurso, ya sean palabras o imágenes, en los que cabe incluir la dimensión geográfica de las obras literarias.

En definitiva, la Geografía Cultural vive en la actualidad un proceso de renovación, en el cual no son extrañas las críticas por parte de los seguidores de las escuelas clásicas y de otras maneras de hacer geografía. Esta transformación de la subdisciplina se traduce en la ampliación de sus límites, tanto conceptuales como metodológicos y de sus contenidos.

- Los objetos de estudio, restringidos hasta los años setenta del pasado siglo a los ámbitos rurales y civilizaciones primitivas, se amplían, incorporando a las sociedades industriales y urbanizadas. Asimismo, se desarrollan las ideas iniciales de Vidal de la Blache, de manera que se abandonan las posturas de rechazo que tanto la Escuela de Berkeley como la Geografía alemana mantenían respecto a los componentes sociales no perceptibles por los sentidos. La Geografía Cultural pasa, de esta forma, a incorporar ideologías, política y pensamiento individual entre sus conceptos básicos.

- Si bien el método empírico sigue constituyendo la base de la Geografía Cultural, se incorporan nuevas metodologías, provenientes de las diferentes «formas de hacer geografía». El humanismo, la geografía de la percepción, las técnicas del positivismo, se incorporan al bagaje de la Geografía Cultural. Asimismo, se profundiza en la visión multidisciplinar de la cultura, incrementándose el contacto con otras disciplinas y profesionales como etnógrafos, semiólogos, psicólogos o sociólogos.

- En cuanto a las escalas de trabajo, la ampliación de horizontes ha supuesto un incremento de la precisión escalar para la geografía cultural. El interés por lo local permanece, reforzado por la valorización del lugar en relación con la necesidad del hombre de identificarse con un espacio determinado, dentro de un contexto de progresiva homogeneización de las pautas culturales. Sin embargo, el mismo proceso de la globalización, ha llevado a los culturalistas a interesarse por escalas más pequeñas de trabajo, aunque sólo fuese con la intención de matizar y evidenciar los peligros del mismo. 
Las críticas a la «Nueva Geografía Cultural» hacen alusión al propio olvido de los autores clásicos — Sauer, Vidal, Passarge, Schlüter- (PRICE y LEWIS, 1993), al incremento del peso adquirido por los factores económicos en los análisis culturales (SAYER, 1994), a la «desespacialización» de los estudios que inciden más en los textos que en los territorios (PALMER, 1990), a la debilidad de algunos conceptos manejados (como los de identidad, representación, ideología) (GREGSON, 1995), incluso se ha señalado el elitismo intelectual y la inaccesibilidad de algunas de sus formulaciones.

Tomando en consideración la diversidad de críticas, las dudas respecto a los enfoques, la diversidad de metodologías aplicadas, la casi infinitud de los objetos de conocimiento cabría plantearse si, realmente, el concepto de cultura, su amplitud y variedad, permite, a comienzos del siglo XXI, la individualización y la identificación de una subdisciplina bajo la denominación de Geografía Cultural o, no es más apropiado referirse a unas geografías de enfoque cultural.

\section{El fin de la geografía (¿es necesaria la geografía a comienzos del siglo XXI?)}

Hace ahora tres lustros, el politólogo estadounidense Francis Fukuyama publicaba la primera versión de su provocadora reflexión sobre «El fin de la historia» y aunque recogía una idea que subyacía en la obra de pensadores anteriores (Hegel, Cournot, Aron, Kojève, Habermas, entre otros), supuso una revolución en el pensamiento histórico y político del momento, en plena disolución de los regímenes comunistas de la Europa del Este. Se trataba de un argumento de oportunidad lanzado en el momento idóneo que animó la reflexión sobre el valor de las ideologías en el epílogo del siglo XX. Evidentemente la Historia, por propia esencia, no puede tener fin, pero sí las ideologías que la adornan en cada momento histórico. Estas últimas cambian, se empobrecen y se renuevan... se suceden las etapas de crisis de unos valores y el surgimiento de otros que intentan racionalizar la explicación de la vida del hombre en la Tierra. En suma, queda siempre la esencia cronológica de los avatares del ser humano, el «cuándo»; cambia la manera de entender ese «cuándo».

De igual modo, la geografía no puede tener final porque forma parte de la esencia de la Naturaleza; es uno de esos conocimientos «innatos» imprescindibles para el ser humano. Es el «dónde» del sistema de referencia básico para la existencia del hombre en la Tierra. Ha estado siempre presente en el universo de saberes de las sociedades y, desde su consolidación como disciplina científica, ha sobrevivido a corrientes y modas, enriqueciendo su corpus teórico y diversificando sus aplicaciones prácticas.

Y ese «dónde», que dice razón de la esencia del ser humano, es cambiante; por eso necesita constante interpretación. La geografía debe estar presente en las enseñanzas fundamentales del hombre. Y, además, resulta tan rápido y continuado el proceso de incorporación de nuevos temas en la lectura del territorio que siempre estará de moda. Siempre vamos a tener la difícil misión de presentar los contenidos principales que deben integrar la formación geográfica básica de los ciudadanos. Y estos contenidos cambiarán como lo hace, de manera constante, la faz de la tierra, las masas de agua que la componen y el medio aéreo que la rodea. Son los fines de una disciplina científica que no tiene fin.

Y ello a pesar de que la aparición de una manera de interpretar los hechos geográficos, lo que se ha venido en denominar "paradigmas», ha intentado acallar —e incluso, desprestigiar- las formas anteriores de hacer geografía. Debe quedar claro que no hay una interpretación exclusivamente liberal o marxista en geografía, o mejor, no debe haberla. Hay —o debe haber - una aproximación ética a los hechos y problemas territoriales que afectan a la existencia del hombre en la Tierra. Si esta aproximación tiene lugar realmente desde esa imprescindible actitud ética de respeto a los derechos y deberes del hombre y de 
la naturaleza, y de respeto, asimismo, a los valores de la geografía, el resultado de todo intento de comprensión de la realidad ira más allá de las sesgadas interpretaciones impuestas por las ideologías. Dicho de otro modo, todo estudio de un hecho geográfico, si se pretende completo, integral e integrador, debe incluir en sus adecuadas proporciones aproximaciones radicales, liberales, humanistas, behavioristas, historicistas, culturalistas y de todas aquellas corrientes, «filosofías» que, en el presente o en el futuro, ofrezcan pautas para la interpretación ética de los hechos geográficos. Y todo ello desde una independencia de criterio necesaria para elegir aquellos prismas de acercamiento que permitan obtener una aproximación a la realidad territorial lo menos «ideologizada» posible.

Debe reconocerse, no obstante, que ha habido y hay geógrafos comprometidos con la sociedad de su tiempo, desde ópticas políticas diversas, generalmente de izquierdas; son personas que aplican, en su vida cotidiana, los principios de la ideología que defienden. Se trata de colegas que representan un ejemplo de coherencia para el resto del colectivo geográfico y que, sólo por ello, merecen la mayor de las consideraciones personales e intelectuales. Otro caso muy distinto son los que predican y no dan trigo, esto es, los que difunden las excelencias de una ideología, porque resulta una moda, y desarrollan, sin embargo, unas actuaciones poco acordes con aquellos principios. Estos son los que menos contribuyen al avance del pensamiento geográfico, porque su falta de compromiso con las ideas que predican se sustituye, en ocasiones, con elucubraciones mentales, que no aportan nada nuevo al edificio epistemológico de la geografía.

Imprimir un sesgo de ideología al análisis de los problemas geográficos supone limitar, de entrada, la visión amplia que debe tener el geógrafo en sus investigaciones. Pero esta apuesta por una actitud ética y libre (no liberal) de la explicación de los hechos geográficos, aunque deseable, es un acto voluntario. A sabiendas de lo empobrecedores que resultan las aproximaciones exclusivamente liberales o exclusivamente marxistas o neo-marxistas, debe reconocerse el carácter «político» del ser humano y su libertad de elección de aquellas ideologías que se aproximen a su filosofía de vida. Otra cosa es que ello resulte adecuado para pretender interpretaciones integrales de los hechos geográficos. Y menos, como se ha señalado, cuando se utilizan argumentos ideológicos para desprestigiar aquellos análisis de la realidad geográfica que no comparten esas formas de aproximación a la misma. Y lo peor, cuando esos supuestos ideológicos que argumentan un ejercicio crítico no se practican como filosofía de vida ni se prestigian como actitud de pensamiento. Esto es, se utilizan coyunturalmente las ideologías y no hay reparos en cambiar de modo de ver las cosas, si es necesario, años después.

Hacer geografía es, en definitiva, preocuparse por interpretar el mundo, es indagar sobre las relaciones entre el medio y el hombre y explicar cómo se reparten estas relaciones diversas en la superficie terrestre. Lo demás es elucubrar, a menudo sin sentido; en suma, hacer lo que no debe ser la geografía. Debemos dedicarnos a hacer geografía pero ello implica siempre conocer las corrientes - antiguas y nuevas - que se aproximan al edificio del pensamiento geográfico para aprovechar aquellas ideas que puedan completar nuestros análisis territoriales. No se concibe a un geográfo - sobre todo docente universitario- que no conozca con profundidad las bases epistemológicas de su ciencia. Es como construir un edificio sin cimentación de base; está condenado al derrumbe. Y debemos estremecernos si escuchamos alardear de ese desconocimiento con el argumento de que ese «rollo» filosófico no sirve de nada. Esos colegas merecen desaprobación y lástima por su aldeanismo. Cuestión distinta son las interpretaciones parciales e interesadas que se puedan hacer de ellas, asimismo reprobables. Debemos defender la utilidad del pensamiento geográfico y su necesidad en el devenir de la disciplina. Debemos centrar nuestra reflexión sobre cómo debe hacerse la geografía y, a continuación, ponerlo en práctica. En última instancia, la geografía o se entiende o no se entiende, o se hace o no se hace, o se sabe hacer o no se sabe hacer, sin 
más. Seamos geógrafos porque hagamos GEOGRAFÍA y, eso sí, no malgastemos más tiempo del necesario en elucubraciones mentales «ideologizadas» que no aportan nada al avance de nuestra ciencia.

Como señalaba hace unos años T. Unwin (1995), cuando nos pregunten a qué nos dedicamos, «debemos ser capaces de decir con confianza — añadiríamos, con convencimiento- que somos geógrafos; que nos ocupamos de algunas de las cuestiones más vitales que se plantean en la sociedad contemporánea».

Bien es cierto, como indica Ortega Valcárcel, que la relevancia o irrelevancia de la geografía en la sociedad moderna no depende de lo que digan los geógrafos, más o menos autocomplacientes sobre sus bondades, sino de la imagen que el conjunto de la sociedad se haga de ella, en la medida en que la contemple como un saber propio del mundo moderno o como una simple reliquia del saber del pasado. La relevancia social de la geografía, su reconocimiento por parte de la colectividad como un saber válido, depende, en gran medida, de su capacidad para presentarse como un campo de conocimiento definido, con perfiles propios ${ }^{14}$.

El momento actual es importante, porque los problemas de carácter territorial, los que tienen que ver, como señala Ortega, con las preocupaciones de la geografía, han adquirido una considerable presencia social. Señalaba Brunet, en 1993, que «la geografía se mueve. Su nombre mismo ha conocido momentos de discreción, por no decir de abandono; ha dejado de ser tabú y vuelve con fuerza hasta en los medios de comunicación». El que así sea depende la propia capacidad de los propios geógrafos para comprender su disciplina y trasmitir sus posibilidades a la sociedad.

Apostemos, hoy más que nunca, por la geografía, recuperemos el sentido global de la disciplina a fin de obtener el conocimiento más elevado de las relaciones hombre-medio que se dan sobre cada porción de la superficie terrestre. Los nuevos temas que se plantean a la disciplina (medio ambiente, paisaje, alteraciones climáticas, contaminación ambiental, nuevo orden mundial, estrategias territoriales) así lo requieren. Recuperemos, en suma, como señalara hace unos años Stoddart la «gran tradición de nuestra disciplina», esto es, la preocupación por el territorio y por la vida. Los geógrafos debemos «elevar las miras»; hablar alto, por encima de nuestras fronteras disciplinares, sobre las grandes cuestiones actuales.

La Geografía no tiene fin, pero si finalidad; y una finalidad social clara y precisa. Estamos llamados a afrontar las cuestiones - muy a menudo problemas - territoriales derivadas de la propia presencia del hombre sobre la Tierra; cuestiones que unas veces precisan un análisis detallado de los elementos del medio físico, otras, de los propios grupos sociales y siempre un estudio de las formas de organización que elige el hombre en cada momento histórico en relación con su herencia cultural. El geógrafo está llamado a dar ideas que permitan mejorar constantemente la manera en que el hombre organice su implantación en la superficie terrestre y sus sistema de relaciones con la naturaleza y con otros hombres.

Debemos tener claro los fines de la geografía que pueden sintetizarse del modo siguiente:

- Analizar los accidentes geográficos —o el medio físico en sentido amplio- que se dan en la Tierra; sus alteraciones y cambios, siempre en relación con el hombre

- Interpretar los movimientos y las formas de agrupación de los seres humanos sobre la superficie terrestre, teniendo en cuenta que la consolidación de grupos sociales lleva aparejada la implantación de un sistema de administración política.

- Estudiar los efectos territoriales de las actividades económicas, sin necesidad de plantear la planificación económica del territorio.

- Valorar el papel de la ciudad como «organismo» que estructura el territorio.

14 Vid. ORTEGA VALCÁRCEL, J. (2001): Los horizontes de la geografía. Ed. Ariel, Barcelona, pp. 553-555. 
- Aportar ideas para la mejora de las relaciones del hombre con la naturaleza.

- Preparar los contenidos para la formación de futuros geógrafos; y, en sentido amplio, elaborar las enseñanzas geográficas básicas que debemos transmitir a los ciudadanos en cada momento.

- Representar cartográficamente, de forma adecuada, esto es, rigurosa y clara al tiempo, los hechos geográficos que se estudian en un territorio.

Yi-Fu Tuan sintetiza, de manera acertada, en su reciente ensayo sobre las formas de evasión del mundo actual los grandes temas de la geografía que, en su opinión, son básicamente dos: la transformación de la naturaleza por parte del hombre y las migraciones. Ambos aspectos se pueden resumir según este autor en un concepto: escape o escapismo, esto es, huida del hombre en torno a los dos elementos principales del quehacer geográfico: la naturaleza y la cultura, («la cultura como huida de la naturaleza y el retorno a la naturaleza en sí, como huida hacia la cultura», TUAN, Yi-Fu, 2003: 121).

El análisis geográfico siempre se realiza bajo un sistema espacial de referencia. Todo geógrafo cimienta sus estudios en una organización social sobre el territorio. Y tanto una, como el otro, son, por naturaleza, cambiantes. La geografía de espacios regionales «de geometría variable» es, tal vez, la expresión más elaborada de la labor geográfica, es la plasmación de las ideas sobre interpretación de unidades territoriales, de escala diversa, en las que se producen relaciones entre los elementos del medio físico y la acción de los grupos sociales que en ellas se asientan y que persiguen una organización jerarquizada de procesos que proporcionan las bases de su sustento y bienestar. Es, en definitiva, la GEOGRAFÍA en su pleno sentido.

Llegar al análisis preciso de los pormenores que dan sentido a un espacio regional, dar relato a esa trabazón de hechos físicos y humanos que se presentan en un medio geográfico es la labor más difícil que se puede desarrollar desde la geografía. En definitiva, el geógrafo se diferencia de otros profesionales que actúan en el territorio porque sabe $-\mathrm{O}$ al menos intenta - leer el territorio de forma integral, relacionando hechos físicos y humanos, para comprender una realidad en continuo cambio.

Debemos ser conscientes, además, de que en el actual proceso de renovación, la región, como marco básico de los estudios geográficos, ha perdido el referente escalar fijo que caracterizaba los estudios de las regiones naturales o las regiones político-administrativas, desde los orígenes de la propia geografía. Y esto no es un obstáculo para la labor de análisis e interpretación de los espacios regionales; antes al contrario, el geógrafo regional actual es capaz de interpretar hechos geográficos que se producen en escalas grandes y pequeñas, puede realizar el tránsito de lo mundial a lo local sin perder —o al menos así debe ser- sentido de la significación geográfica de los hechos. Dollfus señaló hace unos lustros que el método comparativo es una de las grandes armas de trabajo del geógrafo. En este sentido, todo geógrafo debe ser capaz, en este contexto, de dar sentido geográfico a los análisis de espacios regionales tengan la escala que tengan. O dicho de otra manera, debemos tener la habilidad para seleccionar de forma correcta la escala de trabajo que mejor se adapte a los estudios de unidades territoriales, en virtud de la finalidad del análisis que se lleve a efecto. Pero debe quedar claro que todo ello tiene su origen en la región, como concepto, entendida como forma de organización social jerarquizada en un espacio geográfico que depende de tres factores: la herencia histórica, la cultura que impregna a sus actores (sociedades) y el progreso tecnológico ${ }^{15}$.

15 Vid. MARCHAND, P. (2001): «La géographie régionale à l'orée du IIIe millénaire», Annales de Géographie, no 619, Armand Colin, París, pp. 303-308. 
En este contexto las corrientes geográficas surgidas a lo largo de la centuria pasada, han ido aportando nuevas ideas al análisis geográfico. Si la región «clásica» proporcionó los cimientos del concepto de región y de los estudios regionales, la geografía cuantitativa otorgó nuevos métodos y herramientas para el análisis de fuentes de trabajo de la geografía regional (estadísticas); la vertiente coremática de la geografía ha supuesto, desde los años setenta, la incorporación de nuevas formas de representación de las relaciones entre los espacios regionales que debe valorarse como una aportación didáctica incuestionable. Las ideas radicales nos han acercado a la problemáticas sociales de la región, ha permitido el desarrollo de estudios sobre la solidaridad regional, desde una visión de compromiso que debe ser condigna al geógrafo; la aproximación humanística ha revitalizado la interpretación histórica que subyace a los espacios regionales y ha otorgado un interesante punto de vista sobre el papel del hombre, desde su escala más próxima, a la construcción de la mentalidad regional. Los estudios regionales desde la geografía cultural, si se entienden bien, pueden incorporar, por ejemplo, el valor patrimonial de los paisajes como elemento de apreciación de un espacio regional; como señala Vallega (2003) el espacio es una porción de la superficie terrestre que se define por la presencia difusa de determinados símbolos y valores que convertimos en categorías conceptuales.

Y un último apunte, que tal vez debería ocupar apartado primero de esta reflexión: la apuesta por la utilidad de los conocimientos que se investigan en la tarea geográfica cotidiana debe ser objetivo básico para el geógrafo comprometido con su ciencia. No es una cuestión nueva. Debe recordarse el carácter utilitario de la geografía desde sus orígenes en la Grecia clásica, la propia importancia de las Sociedades Geográficas en la divulgación de la labor geográfica y del fomento de expediciones en territorios «desconocidos», las ideas de Hettner sobre el carácter práctico de la geografía, manifestada en su obra $L a$ Naturaleza y los cometidos de la Geografía (1927) y la consolidación de una geografía aplicada con método de trabajo serio desde la posguerra de la segunda guerra mundial en el mundo occidental. El mencionado Hettner, uno de los geógrafos que mejor ha entendido la labor geográfica, señalaba, con gran acierto, en la citada obra que «no deja de ser un error cuando algunos científicos intentan desvincular totalmente a la ciencia de la vida».

Diversos autores han señalado que el geógrafo debe ser un hombre de acción, un hombre de su tiempo, que se involucra con los problemas de la sociedad en que le ha tocado vivir; cada cuál desde su ideario político y sus convicciones morales, pero siempre con la idea clara de la contribución a la mejora de la calidad de vida de los grupos humanos que viven, en cada momento, en un espacio geográfico.

La apuesta por una geografía aplicada es, hoy por hoy, una cuestión insoslayable. Si como colectivo de geógrafos hemos apostado por la geografía aplicada dentro de la estructura educativa que definen los actuales planes de estudio $-\mathrm{y}$ los que van a venir en un futuro próximo-, debemos contribuir a desarrollar esta línea educativa de finalidad utilitaria. Es preciso, pues, avanzar en los métodos de enseñanza que deben emplearse para explicar los nuevos contenidos, así como en los métodos de investigación, que deben ajustarse a los requerimientos que se demandan en un trabajo aplicado. El futuro geógrafo práctico no sólo debe ser capaz de realizar diagnósticos certeros de una realidad territorial debe, como buen galeno, proponer el tratamiento adecuado a cada situación. Y ello se adquiere recibiendo una buena formación en materias aplicadas en las aulas, fomentando la realización de prácticas profesionales en empresas o Administraciones como tarea formativa complementaria de la licenciatura, con la realización, una vez obtenida la licenciatura, de trabajos aplicados y con la formación continua en nuevas técnicas y temáticas geográficas que puedan ir apareciendo en cada momento. 
El geógrafo aplicado debe ser el mejor de los geógrafos posibles. Su compromiso con la sociedad y la situación de desventaja con la que parte respecto a otros profesionales, le obligan a intentar ser siempre el mejor. Y este es el gran reto de los futuros geógrafos. En solitario o integrando equipos multidisciplinares, el geógrafo que participe en trabajos aplicados tiene mucho que decir. La visión de síntesis y el método comparativo son dos de las grandes virtudes de adornan la labor geográfica. Sin olvidar la gran baza geográfica que supone la representación cartográfica en los trabajos aplicados. Despreciar este aspecto a la hora de formar a las nuevas generaciones de geógrafos sólo puede entenderse desde la ignorancia de lo que es la práctica de la geografía o desde seguridad que otorga el puesto laboral estable en el despacho universitario; no desde el compromiso ético con la sociedad del momento que demanda respuestas ante los procesos territoriales siempre cambiantes.

No debemos obviar una última cuestión: tenemos la difícil tarea de preparar, hoy, los contenidos geográficos que se mostraran a las generaciones del próximo siglo, en definitiva, de elaborar la geografía del siglo que ha principiado; una disciplina científica que muestre al hombre en relación con el medio y la sociedad en la que vive, que presente los problemas e inquietudes que ello supone, otorgándole, en suma, las claves para que pueda mejorar sus condiciones de vida perjudicando lo menos posible su ambiente natural.

En 1930, Ortega y Gasset señalaba que la misión de la Universidad debía consistir en hacer del hombre medio, ante todo, un hombre culto, situarlo a la altura de los tiempos. Por eso, para Ortega «la función primaria y central de la Universidad es la enseñanza de las grandes disciplinas culturales»; e indicaba el filósofo cuáles eran estas enseñanzas:

- Imagen física del mundo

- Los temas fundamentales de la vida orgánica

- El proceso histórico de la especie humana

- La estructura y funcionamiento de la vida social

- El plano del universo

No debe ignorarse que varias de estas grandes disciplinas culturales tienen mucho de Geografía. Pero ello se ha olvidado pronto en el sistema educativo español. Resulta utópico pensar en un cuerpo común de enseñanzas comunes a todas las titulaciones universitarias; es impensable suponer, incluso, que puede haber un tronco común de materias en las enseñanzas de una misma rama de conocimiento (Humanidades, Ciencias Sociales). E incluso, asistimos a la defensa del particularismo en el seno de las propias titulaciones. Hoy en día, lamentablemente, no se persigue que el universitario sea un hombre culto sino un hombre práctico. Eso pretende el actual sistema universitario. Y similares consideraciones había que señalar para la enseñanza de la geografía en los niveles educativos no universitarios. Y en este escenario debemos montar nuestra obra educativa.

Al menos debe quedarnos claro que la función primera como docentes es, como señala Inger Enkvist, «enseñar a pensar» a los alumnos ${ }^{16}$. Enseñar a pensar es ayudar a desarrollar la libertad de la persona. El pensamiento necesita de «mimbres» sólidos en materias básicas para la formación de las personas. Y, como señala con acierto el profesor Rodríguez Adrados, el pensamiento occidental está arraigado a las materias humanísticas desde tiempos históricos ${ }^{17}$. Y la geografía es una disciplina importante dentro de aquéllas. Olvidar esto supone condenar a una sociedad al analfabetismo geográfico, a la pérdida del

16 Vid. LEAL, C. (2002): Entrevista a la Enseñanza, Grupo Unión Ediciones, Madrid, pp. 177-185.

17 Vid. RODRÍGUEZ ADRADOS, F. (2002): Humanidades y Enseñanza. Una larga lucha. Ed. Taurus, Madrid, 238 pp. 
sentido de localización. Y esto puede tener unas consecuencias no bien calculadas por la administración educativa española. Estaremos condenados a navegar a la deriva por el Mediterráneo mar, cual Ulises, en busca de una Ítaca ignorada por sus propios moradores.

Tal vez, la aparición en tropel de tantos «paradigmas» en el edificio del pensamiento geográfico ha terminado por provocar hartazgo entre los geógrafos y por ocultar la verdadera finalidad de la geografía. Puede que hayamos asistido - o estemos asistiendo en el momento actual—, al fin de las «ideologías» geográficas, al menos a uno de sus finales, coincidiendo con el momento en que se reclama la unidad de los diferentes modos de entender los hechos geográficos. Y ello puede significar un acicate para que el pensamiento geográfico, en palabras de Fukuyama, comience una vez más. La moderna manera de interpretar la naturaleza como ente que precisa respeto y mantenimiento y a las sociedades como expresión de la cultura del momento, puede ser buen ejemplo de la nueva manera de entender la realidad geográfica. Tuan (2003) nos ha mostrado la posibilidad de entender las relaciones entre el hombre y el medio como una huida, una escapada hacia un mundo - físico y/o espiritual- mejor. Nuevas lecturas sobre el papel de las sociedades en la superficie terrestre que nos recuerdan que estamos ante una ciencia viva, que no olvida, sin embargo, la tradición de la disciplina. La renovación de la tradición, una constante del pensamiento geográfico...

\section{Bibliografía}

AGNEW, J. (1999): «Regions on the mind does not equal regions of the mind», Progress in Human Geography, 23, 1, pp. 91-96.

ALBET I MAS, A. (2001): «¿Regiones singulares y regiones sin lugares? Reconsiderando el estudio de lo regional y lo local en el contexto de la geografía postmoderna» en Boletín de la Asociación de Geógrafos Españoles, no 32 (monográfico sobre la Región y la Geografía Regional), Madrid, pp. 35-51.

ANDERSON, P. (2002): Los fines de la historia. Ed. Anagrama. Col. Argumentos, Barcelona, 175 p. BIRD, A. (2002): Thomas Kuhn. Ed. Tecnos. Madrid. 390 p.

BRUNET, R. et DOLLFUS, O. (1990): Mondes Nouveaux, en Geographie Universelle, Ed. Hachette-Reclus, France, 551 p.

BUNGE, W. (1975): «La ética y la lógica en Geografía». Nuevas tendencias en Geografía. IEAL, pp. 477-500. Madrid.

CALINESCU, M. (2003): Cinco caras de la modernidad. NeoMetropolis. Tecnos/Alianza. Madrid, $325 \mathrm{p}$.

CAPEL, H. (1981): Filosofía y ciencia en la geografía contemporánea, Ed. Barcanova, Barcelona, $509 \mathrm{pp}$.

CHORLEY, R. J. (1987): Nuevas tendencias en geografía, Instituto de Estudios de Administración Local, Madrid, $506 \mathrm{p}$.

CHORLEY, R.J. y HAGGET, P. (1971): La geografía y los modelos socio-económicos. Ed. Instituto de Estudios de Administración Local. Col. «Nuevo Urbanismo». Madrid. 437 p.

CLAVAL, P. (1993): La Geógraphie au temps de la chute des murs, essais et études, L' Harmattan, París, 343 p.

CLAVAL, P. (1999): «Los fundamentos actuales de la geografía cultural» en Documents d'Anàlisi Geogràfica no 34 Monográfico Noves Geografies Culturals, Universitat Autònoma de Barcelona, Departament de Geografia. Universitat de Girona, Secció de Geografía, pp. 25-40.

CLAVAL, P. (1999): La Geografía Cultural, EUDEBA, Buenos Aires, 377 p.

COELHO FERREIRA, C. y NEVES SIMOES, N. (1994): A evoluçao do pensamento geográfico, Ed. Gradiva, Lisboa, 142 p.

COLLIGNON, B. (1999): «La geografía cultural en Francia: un estado de la cuestión» en. Documents d'Anàlisi Geogràfica no 34 Monográfico Noves Geografíes Culturals, Universitat Autònoma de Barcelona, Departament de Geografia. Universitat de Girona, Secció de Geografía, pp. 103-117. 
COSGROVE, D. (1984): Social Formation and Symbolic Landscape, Londres, Croom Helm.

COSGROVE, D. y JACKSON, P. (1987): «New directions in cultural geography» en Area nº 19, pp. 95-101.

DAUPHINÉ, A. (2003): Les theories de la complexité chez les géographes. Ed. Anthropos. Paris, $248 \mathrm{pp}$.

DOLLFUS, O. (1975): El espacio geográfico. Oikos-Tau, Barcelona, 124 p.

DOLLFUS, O. (1978): El análisis geográfico, Ed. Oikos-Tau, Barcelona, 135 p.

DUNCAN, J. (1990): The City as Text: the Politics of Landscapes Interpretation in the Kandyan Kingdom, Cambridge, Cambridge University Press.

DUNCAN, J. (1992): «Re-presenting the Landscape: problems of reading the intertextual» en MONDADA, L.; PANESE, F. y SÖDERSTRÖM, O. (Dirs.) Paysage et crise de la lisibilité, Lausanne, Université de Lausanne, Institut de Géographie, pp. 81-93.

FARINOS DASÍ, J. (2001): «Reformulación y necesidad de una nueva geografía regional flexible», en Boletín de la Asociación de Geógrafos Españoles, ㄲo 32 (monográfico sobre la Región y la Geografía Regional), Madrid, pp. 53-71.

FEBVRE, L. (1955): La evolución de la humanidad. Unión Tipográfica Editorial Hispano Americana. México. 377 p.

FRÉMONT, A. (1976): La région espace, vécu. Presses Universitaires de France, Paris, 223 p.

GARCÍA Ál VAREZ, J. (2002): Provincias, Regiones y Comunidades Autónomas. La formación del mapa político de España; Temas del Senado (Secretaría General del Senado, Dirección de Estudios y Documentación, Departamento de Publicaciones); Madrid; 776 p.

GARCÍA FERNÁNDEZ, J. (2000): «La región y los cambios regionales en España»; Investigaciones Geográficas, ํㅡㄹ 24; pp. 5-15.

GARCÍA RAMÓN, M. D., NOGUE I FONT, J. y ALBET I MAS, A. (1992): La práctica de la geografía en España, Ed. Oikos-Tau, Barcelona, 250 p.

GARNIER, J.P. (1980): «Espace marxiste, espace marxien». L'Espace Géographique (4), pp. 207-275.

GEORGE, P. (Coord.) (1980): Geografía Activa. Barcelona, Ariel.

GÓMEZ MENDOZA, J. (2001): «Un mundo de regiones: Geografía regional de geometría variable», Boletín de la Asociación de Geógrafos Españoles, no 32 (monográfico sobre la Región y la Geografía Regional), Madrid, pp. 15-33.

GREGSON, N. (1995): «And now it's all consumption?». Progress in Human Geography 19, pp. 135-141.

HAGGETT, P. (1987): Geografía: una síntesis moderna. Ed. Omega, Barcelona.

HARTSHORNE, R. (1991): «El concepto de geografía como ciencia del espacio: de Kant y Humboldt a Hettner», en Documents d'Anàlisi Geogràfica, Publicacions del Departament de Geografia, Universitat Autònoma de Barcelona, Barcelona, pp. 31-54.

HERBERTSON, A. J. y F. D. (1935): Geografía Humana, Ed. Seix Barral, Barcelona, 159 p.

HETTNER, A. (1987): «La naturaleza y los cometidos de la Geografía». Geocrítica, no ${ }^{\circ}$, Universitat de Barcelona, Barcelona. 79 p.

JACKSON, P. (1999): «¿Nuevas geografías culturales?» en Documents d’ Anàlisi Geogràfica no 34 Monográfico Noves Geografíes Culturals, Universitat Autònoma de Barcelona, Departament de Geografia. Universitat de Girona, Secció de Geografía, pp. 41-51.

JOHNSTON, R. J. (1994): Geography and Geographers. Anglo-American Human Geography since 1945, Edward Arnold, London, $361 \mathrm{p}$.

KRAMSCH, O. (1999): «El horizonte de la nueva geografía cultural» en Documents d'Anàlisi Geogràfica no 34 Monográfico Noves Geografíes Culturals, Universitat Autònoma de Barcelona, Departament de Geografia. Universitat de Girona, Secció de Geografía, pp. 53-68.

KUHN, T. S. (1975): La estructura de las revoluciones científicas. F.C.E. México.

KUHN, T. S. (1996): ¿Qué son las revoluciones científicas? y otros ensayos. Piados I.C.E./U.A.B. Barcelona. $151 \mathrm{p}$.

LABASSE, J. (1973): La organización del espacio. Madrid, Instituto de Estudios de Administración Local.

LÓPEZ TRIGAL, L. y BENITO DEL POZO, P. (1999): Geografía Política. Madrid, Cátedra, Serie Geografía Menor, 304 p. 
MATLESS, D. (1995): «Culture run riot?: work in social and cultural geography», Progress in Human Geography 19 (3), pp. 395-403.

MINSHULL, R.(1967): Regional Geography: theory and practice. Hutchinson Library. Londres.

MONDADA, L. y SÖDERSTRÖM, O. (1993): «Parcours à travers de la géographie culturelle contemporaine» en Géographie et Cultures, vol. 2, no 8, pp. 71-82.

NOGUÉ, J. y RUFÍ, J. V. (2001): Geopolítica, identidad y globalización. Edit. Ariel, Barcelona, $247 \mathrm{p}$.

OLCINA CANTOS, J. (1996): «La Geografía hoy: Reflexiones sobre el pensamiento geográfico, la región y la docencia de la Geografía». Investigaciones Geográficas, ํㅡㄴ 16, pp. 93-114.

ORTEGA CANTERO, N. (1988): Geografía y cultura, Alianza editorial, Madrid, 121 p.

ORTEGA VALCÁRCEL, J. (2000): Los horizontes de la Geografía. Teoría de la Geografía; Ed. Ariel; Barcelona; 604 p.

PAASI, A. (2000): «Europe as a social process and discourse: considerations of place, boundaries and identity». Ponencia invitada en The Third European Urban and Regional Studies Conference, celebrada en Voss, Noruega, del 14-17 de septiembre, 29 p.

PHLIPPONNEAU, P. (2001): Geografía aplicada. Editorial Ariel. Colección Geografía. Barcelona, $320 \mathrm{p}$.

PINCHEMEL, Ph. e G. (1996): Dal luogo al territorio. Fondamenti di geografia regionale. FrancoAngeli, Milano, $94 \mathrm{p}$.

PRED, A. (1991): «Other studies» Journal of Historical Geography, 17, pp. 115-117.

PRICE, M. y LEWIS, M. (1993): «The reinvention of cultural geography» Annals of the Association of American Geographers, 83 (1), pp. 1-17.

PUJADAS, R. y FONT, J. (1998): Ordenación y planificación territorial, Madrid, Editorial Síntesis, $399 \mathrm{p}$.

SANTOS, M. (1990): Por una nueva geografía, Ed. Espasa-Calpe, Madrid, 257 p.

SAYER, A. (1994): «Cultural studies and the economy, stupid», Environment and Planning D: Society and Space, 12, pp. 635-637.

SCHAEFER, F. K. (1974): Excepcionalismo en Geografía. Ediciones de la Universidad. Barcelona. (introducción a cargo de H. Capel).

STODDART, D.R. (1987): «To claim the high ground: geography for the end of the century». Transactions of the Institut of British Geographers, vol. 12 (3), pp. 327-336.

STODDART, D.R.(1982): «El concepto de paradigma y la historia de la Geografía». Geocrítica, 40, Universitat de Barcelona, pp. 9-19.

TERÁN, M. de (1982): Pensamiento geográfico y espacio regional en España, Ed. de la Universidad Complutense de Madrid, $454 \mathrm{p}$.

TROCHET, J. R. (1993): Aux origines de la France rurale. Outils, pays et paysages. Paris. Éditions du CNRS.

TUAN, Yi-Fu (2003): Escapismo. Formas de evasión en el mundo actual. Ed. Peninsula/Altaya, Barcelona, $301 \mathrm{p}$.

UNWIN, T. (1995): El lugar de la Geografía. Madrid, Cátedra, 342 p.

VALLEGA, A. (1989): Compendio di geografia regionale, Ed. Mursia, Milano, 222 p.

VALLEGA, A. (2003): Geografia culturale. Luoghi, spazi, simboli. UTET Libreria, Torino, 381 p.

VV.AA. (2001): Región y Geografía Regional (número monográfico, no 32, del Boletín de la Asociación de Geógrafos Españoles), Madrid, 272 p. 